\title{
DOCUMENTAR LA SEXUALIDAD Y LA DIVERSIDAD FUNCIONAL. EL SEXO Y LOS CUERPOS DIVERSOS Y NO NORMATIVOS COMO ARMAS DE EMPODERAMIENTO Y REIVINDICACIÓN POLÍTICA EN YES WE FUCK!, JO TAMBÉ VULL SEXE! Y CRIP CAMP
}

\author{
Hernando Carlos Gómez Prada y Marcos Bote Díaz \\ hergo22@hotmail.com_mbote@um.es
}

Universidad de Murcia

\section{RESUMEN}

El género documental es un cine subjetivo y reivindicativo que ha sido utilizado para prácticas activistas desde su creación, ampliando miradas, rompiendo tabúes y mostrando realidades diferentes, ricas y plurales. Los documentales Yes we fuck!, Jo també vull sexe! y Crip Camp tienen en común la visibilización del potencial político de los cuerpos en rebelión. En este artículo se realizará un estado de la cuestión acerca de la relación entre sexualidad y diversidad funcional para más adelante realizar un análisis audiovisual, con un enfoque cualitativo e interdisciplinar de los documentales seleccionados, poniendo especial énfasis en las transgresiones sociales que significa mostrar abiertamente las sexualidades y los cuerpos diversos. Entre los principales resultados, cabe destacar la forma en que el género documental aumenta el grado de empoderamiento personal y colectivo y termina convirtiéndose en un arma de reivindicación política.

Palabras clave: cine, documental, sexo, diversidad funcional, empoderamiento.

DOCUMENT SEXUALITY AND FUNCTIONAL DIVERSITY. SEX AND DIVERSE, NON-REGULATORY BODIES AS WEAPONS OF EMPOWERMENT AND POLITICAL VINDICATION IN YES WE FUCK!, JO TAMBÉ VULL SEXE! AND CRIP CAMP

\section{Abstract}

The documentary genre is a subjective and vindictive cinema that has been used for activist practices since its creation, broadening viewpoints, breaking taboos and showing different, rich and plural realities. The documentaries Yes we fuck!, Jo també vull sexe! and Crip Camp have in common the visibility of the political potential of bodies in rebellion. In this article, we will present a state of the art on the relationship between sexuality and functional diversity. We will then carry out an audiovisual analysis, with a qualitative and interdisciplinary approach, of the selected documentaries, placing special emphasis on the social transgressions that mean openly showing sexualities and diverse bodies. Among the main results, it is worth highlighting the way in which the documentary genre increases the degree of personal and collective empowerment and ends up becoming a weapon of political vindication.

Keywords: Film, Documentary, Sex, Functional Diversity, Empowerment. 


\section{INTRODUCCIÓN / MARCO TEÓRICO}

El asunto que nos aborda, sexualidad y discapacidad, se conforma, como se verá en las líneas siguientes, como un tabú profundamente incrustado en la socie$\mathrm{dad}^{2}$. Numerosos especialistas plantean que no se haya prestado atención a estudiar, en general, las demandas sociales de las personas con discapacidad, tratándolas siempre desde un paradigma mayoritariamente médico (Sandahl, 2003; McRuer, 2003). De este modo, aunque existe una revista científica desde 1978 titulada Sexuality and Disability, se trata de una publicación que aborda los aspectos médicos y psicológicos de la sexualidad en relación con la discapacidad. Un análisis de las publicaciones de esta revista entre 1996 y 2006 confirmaba esa percepción del cuerpo y la sexualidad de las personas con discapacidad ${ }^{3}$ como limitadas (Meinerz, 2010).

A pesar de los avances en la integración de las personas con discapacidad en la sociedad, la percepción social sobre su sexualidad permanece anclada en tabúes y prejuicios. Algunos autores han recogido (Shakespeare, 1998; Brodwin and Frederick, 2010) una serie de mitos y prejuicios sobre el binomio sexualidad/discapacidad que muestran claramente que existe un total desconocimiento por parte de la sociedad e, incluso, en algunos casos un alto grado de discriminación:

- Son asexuales o, en el mejor de los casos, sexualmente incompetentes. En cualquier caso, muestras de expresión sexual por su parte serían inadecuadas.

- No pueden ovular, menstruar, concebir ni dar a luz, tener orgasmos, erecciones, eyaculaciones ni fecundar.

- Si no están casados o en una relación estable es porque nadie los quiere (o no son atractivos), y no como fruto de una decisión personal de permanecer solteros o vivir solos.

- Si no tienen un/a hijo/a debe ser causa de profunda lástima, e igualmente nunca se puede deber a una elección propia.

- Cualquier persona no discapacitada que se case con alguien con diversidad funcional lo tiene que haber hecho por algún motivo sospechoso, nunca por amor.

- Si la pareja es también discapacitada, se han juntado precisamente por esa circunstancia, y no por otra cualidad que se pueda poseer. Cuando se escoge

${ }^{1}$ Centeno, Antonio. (2013): «La revolución de los cuerpos», en http://derechoshumanosya. org/la-revolucion-de-los-cuerpos/. (Consultado el 1/04/2020).

${ }^{2}$ Esta investigación se enmarca en el proyecto «Sexualidad y Diversidad Funcional (SEXFUN)» (Beca Leonardo a investigadores y creadores culturales/Fundación BBVA/2019).

3 A lo largo del artículo se utilizarán indistintamente los términos "personas con discapacidad» $\mathrm{y}$ «diversidad funcional», al no existir consenso sobre el término más adecuado para referirse a las personas que presentan condiciones físicas, intelectuales, sensoriales y emocionales diferentes a lo establecido como norma. 
a los de «su clase» el mundo de los no discapacitados se siente aliviado, hasta el momento en que deciden tener hijos, en cuyo caso se les considera irresponsables.

Estos postulados se enmarcan en el modelo médico rehabilitador, que aparece por primera vez a mediados del siglo xx. Un factor coadyuvante fue la simpatía que despertaban los veteranos de las guerras mundiales. No es hasta final del siglo pasado cuando la sociedad empieza a demostrar su preocupación por la identidad personal, imagen corporal y sexualidad humana como parte de la rehabilitación. En este sentido, el trabajo de Robinault Sex, society and the disabled puede considerarse un trabajo seminal sobre esta cuestión (Robinault, 1979; Cole \& Cole, 1993). Aproximadamente 15 años más tarde Monga (1995) llevaba a cabo un estado de la cuestión (o más bien, no estado de la cuestión, como acertadamente señalaron entonces algunos críticos) y reafirmaba los paradigmas del modelo rehabilitador, con importantes limitaciones que básicamente culpan a la enfermedad, y de forma adyacente al individuo, sin tener en cuenta el exosistema de creencias sociales y culturales que subyace en las concepciones médicas, sociales y políticas de tratamiento de la discapacidad. Todo ello, además, situado en una visión penecéntrica/ coitocéntrica de la sexualidad. Esta visión ha sido, desgraciadamente, la predominante durante la mayor parte de la historia, incluso con anterioridad a la rehabilitación, el paradigma de la institucionalización impuso severas medidas de control social llegando incluso a la esterilización eugenésica de las mujeres discapacitadas (Block, 2002; Fiduccia, 2000).

En las últimas décadas, este modelo biológico ha dado paso paulatinamente a lo que ha venido en denominarse el modelo social de la discapacidad. En este nuevo paradigma se tratan de integrar los componentes sociológicos y culturales de la diversidad funcional. En el caso concreto de la sexualidad, el modelo social se centra fundamentalmente en las limitaciones externas de la misma, sin perder en ningún momento de vista que la diversidad funcional, más allá de una condición médica, es un constructo social, como algunas investigaciones han puesto de manifiesto (Parchomiuk, 2012; Arnau, 2003). El modelo social de la diversidad, denominación acuñada por Mike Oliver en Reino Unido, se encuentra íntimamente ligado al movimiento de vida independiente, movimiento que desde mediados de los años 70 persigue la percepción de los sujetos con discapacidad funcional como ciudadanía de pleno derecho, así como la puesta en práctica de recursos como la accesibilidad universal y la asistencia personal autogestionada para que las personas con diversidad funcional puedan dirigir y controlar sus propias vidas (Arnau, 2005).

Cabe destacar cómo, a raíz del enfoque social de la discapacidad, el estudio sobre esta realidad ha comenzado a converger con otros campos de estudios, especialmente con el estudio del género y la orientación sexual. La crítica al modelo rehabilitador se suele enmarcar principalmente en la óptica foucaltiana. Especialmente desde los enfoques teóricos más críticos, como son la teoría queer y la teoría crip (Platero y Rosón, 2012; García-Santesmases, 2015). En este sentido, desde un enfoque paradigmático posestructuralista tanto la orientación sexual como la diversidad funcional son enmarcadas dentro de un paradigma crítico que cues- 
tiona el orden establecido social y culturalmente, así como él mismo es construido y naturalizado, incrustado en complejas relaciones culturales sociales y económicas y como esta construcción puede ser cambiada, especialmente a través de una economía social y política de la visibilidad (McRuer, 2006).

Esta visión culturalista del cuerpo no es exclusiva de los planteamientos más posmodernos provenientes de los estudios culturales, ya Marcel Mauss anticipa una visión culturalista del cuerpo frente a los mecanismos naturalistas (Mauss, 1968). Planteamientos que desde la antropología han tenido una continuidad en la obra de autores como Le Breton (2002) o Douglas (1988). Siendo abordado, también, desde un punto de vista de las relaciones de dominación y las lógicas de biopoder por autores como Foucault (1992) o Bourdieu (1977), que en el caso del territorio español permanecen muy presentes (Iañez, 2010).

Más recientemente, también se ha abordado el tema desde la perspectiva de los derechos humanos. Así, hay autores que formulan la necesidad de fortalecer los sistemas de salud para que los sanitarios no muestren resistencia o encaren dilemas cuando traten a pacientes con discapacidad, siendo necesaria no sólo la formación, sino una socialización integral de respeto a la diversidad (Mall y Swartz, 2012). Se insiste en esta perspectiva también para las personas con discapacidad intelectual, caracterizada por un discurso de supresión de su sexualidad (Taylor, 2012). En el presente siglo, se comienza a abordar desde una perspectiva más integral la sexualidad de las personas con discapacidad, física o intelectual, poniendo el énfasis en su derecho a una vida sexual satisfactoria y en la dotación de herramientas para evitar el abuso y el asalto sexual tanto de adolescentes como de adultos (Greydanus et al., 2002). Aun así, recientemente seguimos encontrando intervenciones psicológicas basadas en esta concepción terapéutica (Dukes y McGuire, 2009; Healy et al., 2009).

En un esfuerzo por integrar la perspectiva de los derechos humanos, algunos autores han advertido sobre el peligro de centralizar la importancia del sexo frente a la amistad o la intimidad. En este sentido, algunos autores han sugerido la incorporación de la teoría del reconocimiento de Axel Honneth para conceptualizar la sexualidad en la agenda de los derechos de las personas con diversidad funcional (Shakespeare, 2000). De ahí la necesidad de pensar el modelo social de la discapacidad, o más bien repensar, pues durante la primera década del presente siglo el modelo continuaba reforzando la matriz heterosexual con una visión binaria del sexo, apostando por visiones dismodernistas de la sexualidad y la belleza (Rembis, 2010). Parece que aún, en la actualidad, se hace necesaria la articulación de una concepción de la discapacidad en la cultura mainstream a través del desarrollo de políticas sociales que hasta el momento se ha regido fundamentalmente por principios utilitarios y de igualdad libertaria de oportunidades (Shildrick, 2007). Es importante, en esta articulación, integrar el discurso del placer, fundamental para la calidad de vida de las personas con discapacidad (Tepper, 2000).

Dentro de la sexualidad de las personas con discapacidad se ha tornado controvertido el asunto del derecho a la asistencia sexual. Desde el punto de vista jurídico o ético el derecho a la asistencia sexual puede enmarcarse en la teoría de las necesidades, reconociéndose como parte de los derechos sexuales o incluso como el derecho a elegir una forma de vida (De Asís, 2017). 
El cine es un instrumento significativo para la comprensión de la realidad social y debido a su variedad temática es un importante exponente del imaginario social. Walter Benjamin (2003) define el cine como un artefacto cultural de dimensión colectiva que a partir de la reproducción técnica facilita el proceso de alienación sociocultural.

El cine, además de su función lúdica, tiene una función informativa, investigadora y pedagógica que ayuda a crear y transmitir actitudes y valores sociales y culturales. El mundo de la imagen, de la ficción, conecta a través de canales connotativos, y su persistencia determina su aceptación y aportación al imaginario popular (Mitry, 1989)

El cine puede considerarse un instrumento de representación de la sociedad y de las relaciones que en ella se desarrollan y un medio de comunicación de masas (Sorlin, 1977). A través del cine se muestra la diversidad de culturas, con sus pensamientos, modos de vida, costumbres, y nos ofrece la posibilidad de sumergirnos en ellas para "conocerlas, comprenderlas, aceptarlas y respetarlas, con la esperanza de lograr una convivencia donde imperen valores necesarios en la sociedad actual como, la tolerancia y la ciudadanía» (Alonso y Pereira, 2000: 129), pero, además, el cine ha servido de vehículo cultural de la violencia simbólica (Bourdieu, 1999) contra las personas con discapacidad y urge la necesidad de desentrañar sus mecanismos por los cuales estereotipa y discrimina a este colectivo, poniendo el cine en las manos de las personas con discapacidad o buscando miradas no discriminatorias sobre este colectivo.

En el objeto de estudio que nos ocupa, los géneros cinematográficos en los que se inscriben las obras marcan de manera definitoria su enfoque, de esta manera nos encontramos ante dos largos documentales cinematográficos y un reportaje documental televisivo, que debido a sus similitudes con el documental cinematográfico y al compartir muchos elementos dentro de sus estructuras, analizaremos como cine documental.

En el caso de Yes we fuck! (YWF), nos encontramos con una obra audiovisual que va más allá del documental y muestra de una manera conscientemente política actos sexuales, por lo que estaría, además, enmarcada dentro del género pornográfico, o más bien dentro del conocido como movimiento posporno (o postporno), un tipo de pornografía realizada desde una mirada revolucionaria que cuestiona la pornografía mainstream al mostrar cuerpos y prácticas sexuales y eróticas reales, diversas, no normativas y subversivas, siempre desde una referencia feminista o transfeminista.

Jo també vull sexe! (JTVS) pertenece al género documental de entrevistas y está centrado en mostrar la sexualidad de las personas con discapacidad de una manera didáctica y dando la voz a los protagonistas, además, el fin del documental es mostrar al público la figura de el/la asistente sexual. Nos encontramos ante un documental divulgativo dirigido a un público experto, no un público general, debido a que es emitido en un programa especializado. La emisión del documental coincide cronológicamente con el interés por parte de los medios de comunica- 
ción por la figura de el/la asistente; en ese año 2017, encontramos numerosas noticias que se hacen eco de la regulación en Suiza de la asistencia sexual y comienzan a plantearse su implantación en España. Este documental viene a dar voz a los/las asistentes y a las personas con discapacidad que utilizan estos servicios como un medio de visibilizar y abrir el debate social sobre su regularización.

Crip Camp (CC) es un documental híbrido de entrevistas y archivo donde el sexo es tratado de una manera transversal. Hemos decidido incluir este documental como un ejemplo de la evolución de la temática sexualidad y discapacidad en el audiovisual. El tratamiento de la sexualidad en este documental es muy similar al que se concede a la integración, la eliminación de barreras o la reivindicación política. Desde 2015 con YWF hasta 2020 con CC podremos analizar desde una perspectiva histórica cómo la sexualidad ha pasado de ser un tabú a una reivindicación lógica y plausible dentro del audiovisual. A través de una narración clásica y con el uso de flashbacks se narra la historia del campamento de verano donde se gestó el movimiento por los derechos civiles de las personas con diversidad funcional, asistimos a las vidas pasadas y actuales de eminentes activistas que hablan de su sexualidad de una manera desprejuiciada y sin tabúes, como una parte esencial de sus vidas desde que son adolescentes hasta que son ancianos, elaborando un discurso que entrelaza amor y sexualidad de una manera normativa y rompiendo con imágenes anteriores discriminatorias.

\section{ESTADO DE LA CUESTIÓN}

Mucha de la investigación inicial se ha llevado a cabo desde el punto de vista clínico; sin embargo, existen numerosas aproximaciones desde las ciencias sociales. Un estudio pionero es el llevado a cabo en Sudáfrica en 1992 por la académica discapacitada Shanaaz Majiet, quien condujo talleres para conocer la percepción social de las mujeres con discapacidad obteniendo imágenes negativas o de condescendencia (Majiet, 1992, 1996). Más tarde se comenzó a hacer investigación cualitativa, destaca particularmente el trabajo de Yoshida, Lee y Odette (1999) con grupos de discusión con mujeres con discapacidad física de diferentes grupos étnicos. La intersección de desigualdades ha ganado también fuerza en los estudios sobre sexualidad, destacando especialmente los estudios que enlazan los estudios de discapacidad con los estudios queer (Drummond y Brotman, 2014).

Muchos de los estudios de personas con discapacidad se han llevado a cabo a través de cuestionarios con personas con discapacidad, en algunos casos sobre autoconocimiento (Kijak, 2011, 2013), abuso sexual (Nosek et al., 2001), autoestima (Taleporos y McCabe, 2001; Taleporos et al., 2002) o necesidades sexuales (McCabe, 1999; McCabe et al., 2000). También se ha usado la observación participante en bailes para personas con discapacidad intelectual (Löfgren-Martenson, 2004).

Una buena parte de los estudios se ha centrado en conocer la opinión de otras personas, en ocasiones los padres (Isler et al., 2009), estudiantes universitarios (Franco et al., 2012; Parchomiuk, 2012), personal de la industria del ocio (Gilmore y Chambers, 2010), personal de servicios de planificación familiar (Anderson 
y Kitchin, 2000) y, por último, los estudios que han puesto de manifiesto la falta de formación en el colectivo sanitario (Kedde et al., 2012; Shindel et al., 2010 Valvano et al., 2014).

Otros estudios se han centrado en conocer las actitudes y el conocimiento hacia la sexualidad de las personas con discapacidad. Los resultados han mostrado la necesidad de aumentar la formación de los terapeutas en este sentido de forma que se muestren más cómodos al tratar asuntos sexuales con sus pacientes (Sakellariou y Simó, 2006; Kazukauskas y Lam, 2010).

Más recientemente han cobrado notoriedad los estudios usando la perspectiva narrativa. Destacan particularmente los escasos estudios centrados en la asexualidad, libremente elegida, de personas con discapacidad (Kim, 2011). Estudios pioneros sobre la asexualidad de personas autistas (Williams, 1994) contestan el modelo de normalización de la sexualidad de las personas con discapacidad. En el caso de la sexualidad de personas con trastornos del espectro autista también se ha hecho hincapié en la necesidad de adaptar la educación sexual para que los conocimientos sean más fácilmente adquiridos por las personas que experimentan esta condición (Koller, 2000).

En la misma línea de estudios narrativos también aparecieron estudios a principio de siglo sobre la fertilidad de mujeres con discapacidad (Block, 2000) o el impacto de la discapacidad en la masculinidad (Shakespeare, 1999, Tepper, 1999; Guldin, 2000; Sakellariou, 2006). Más recientemente los estudios narrativos, algunos de corte autobiográfico, han cobrado fuerza en la actualidad, centrándose en diferentes condiciones, como el autismo (Block et al., 2012), la discapacidad intelectual y la autodeterminación (Bernert, 2010) o la experiencia como familiar de una persona con discapacidad (Winges-Yanez, 2013). Más escasos, pero también interesantes, son aquellos estudios que han usado el análisis de contenido para aproximarse a la sexualidad de las personas discapacitadas a través de la pornografía (Overstreet, 2008).

En el caso de España, resulta especialmente atractiva la aproximación etnográfica de García-Santesmases y Branco de Castro (2016) en torno a la figura de la asistencia sexual, usando tanto observación participante como entrevistas en profundidad con trabajadoras sexuales, siendo este último grupo un colectivo del que apenas existen estudios sobre la cuestión (Sanders, 2007).

\section{El CiNe COMO REFLEJO DE LOS CAMBIOS SOCIALES}

Juan Cobos, en el prólogo de El cine del aislamiento. El discapacitado en la historia del cine (Norden, 1998: 9), nos advierte que «la forma en que se ha reflejado la discapacidad, en que el cine nos ha guiado en nuestra forma de verla y sentirla. El balance es muy negativo. Aquel que tenía un rasgo físico distintivo ha sido aprovechado para atribuirle maldades, perversidad, odio».

Enrique Martínez-Salanova Sánchez (Ledesma, 2009: 130) retoma la idea de la exclusión y la marginalidad, incidiendo en la necesidad de una visibilización positiva: 
Las personas discapacitadas siempre han estado representadas en el cine, y cada vez más, con mayor fuerza. No obstante, este lenguaje global ha tratado al discapacitado de forma desigual presentándolo, en una gran parte de la filmografía, tanto como ser marginal, deforme y malvado, como el bonachón incapaz de hacer daño a nadie. En el correr de los años, el cine ha avanzado en sus lenguajes promoviendo una figura del discapacitado cada vez más acorde con el sentido que tiene y aporta a la sociedad, tomando de la sociedad los modelos que ésta provee. Sin embargo, el peor maltrato que sufren los discapacitados en el cine es que no se les ve, salvo excepciones, como a cualquier persona.

Como podemos comprobar, la imagen que el cine suele transmitir de la discapacidad es frecuentemente una imagen llena de prejuicios y estereotipos que en escasas ocasiones se acercan a la vida real de estas personas.

Es importante incidir en la importancia capital de la imagen cinematográfica porque el cine que se produce en un país pasa a formar parte de la realidad social de ese país debido a que se construye dentro de una cultura determinada. Esta producción cinematográfica está influida culturalmente por el lugar donde se produce y es reflejo de su política, de su historia o costumbres. En el cine aparece la visión que la sociedad tiene de sí misma y del otro, la imagen cinematográfica es reflexiva, porque sus historias provienen de la sociedad y son un reflejo de ella. Debido a este poder de comunicación social, el estudio del cine y su influencia en los cambios de paradigmas puede llevarnos a conocer cómo se desarrolla una sociedad. Desde este punto de vista el análisis fílmico permite comprender, de cierta manera, el pensamiento y tiempo de la sociedad en la que se ha producido (Goldman, 1976).

Según Kracauer (Ethis, 2009: 53), «el cine puede ser estudiado como reflejo de la sociedad o como documental expresivo del mundo social» y es esta idea la que queremos reflejar en este trabajo, que además se centra en el género documental, un género que, como nos indica Sorlin, «traduce la realidad y donde se presenta lo visible o representable de la sociedad» (Ethis, 2009: 63). Además, al «visibilizar» a la sociedad, el cine se sitúa en el plano de lo cultural y lo social, convirtiéndose así en una herramienta muy útil para cambiar, transformar o denunciar esa sociedad.

Norden (1998), en su libro titulado El cine del aislamiento, detalla los distintos estereotipos con los que las personas con discapacidad han ido apareciendo a lo largo de la historia del cine: desventurado cómico, dulce inocente, vengador obsesivo, villano discapacitado, noble guerrero, santo sabio y ciudadano superestrella. Lamentablemente, algunas de estas visiones estereotipadas siguen apareciendo en la producción cinematográfica de nuestros días.

Garland-Thomson (McRuer, 2006: 171) clasifica cuatro maneras de mirar a la discapacidad: desde el asombro, desde lo sentimental, con lo exótico o transgresivo y la manera realista. La primera nos aleja del sujeto que es mirado, la segunda coloca al sujeto discapacitado en una posición inferior a través de la pena y la compasión del que mira, la tercera hace ver la discapacidad como algo extraño y, por último, la manera realista, que supone un acercamiento a la discapacidad que minimiza las diferencias entre el que observa y la persona discapacitada. Esta última manera sería la manera en la que el documental se acerca a la realidad de la discapacidad. El documental, mostrando la realidad de la discapacidad, nos alerta sobre 
cómo no es la discapacidad, sino la exclusión y la falta de empatía, la que más sufrimiento produce.

La necesidad visual del cine de crear estereotipos para poder comunicar ha logrado durante largo tiempo que la discapacidad haya estado vinculada a la medicina, el terror o la maldad, elaborando el discurso simplista y discriminatorio que ha sido reelaborado desde el documental, un género que logra llegar de una manera más honda y reflexiva al espectador. «El documental puede ser tanto un ensayo premeditado como una expresión lírica e impresionista, es el opuesto al entretenimiento de escape, a la negación de la realidad; por el contrario, está comprometido con la riqueza y la ambigüedad de la vida tal cual es» (Rabiger, 1992: 17). Como observa Breschand (2004: 4) acerca del documental:

Interrogar al cine partiendo de su faceta documental significa interrogarse sobre el estatuto de la realidad frente a la cámara, o la relación entre el filme y la realidad. Significa elegir un eje de reflexión, un eje que supone que el cine se reinventa a sí mismo cuando logra hacer visible algo que hasta entonces había permanecido inadvertido en nuestro mundo.

Además, el cine documental puede desarrollarse de manera diferente al ficcional, es más libre en sus códigos y, gracias a sus presupuestos más reducidos, tiene una mayor capacidad de crear contranarrativas (Chanan, 2007); el documental es político por naturaleza. «El cine documental intenta provocar sentimientos, modificar o fortalecer compromisos y proponer acciones impulsadas por creencias compartidas» (Nichols, 2007: 39).

Esta necesidad de reemplazar las interpretaciones sobre lo que significa tener discapacidad entendiendo estas como construcciones sociales es la principal reclamación que se le formula actualmente al cine y sólo el documental tiene la capacidad de adaptarse a estas urgentes y necesarias reclamaciones.

Mientras toma forma, dirige siempre la cámara hacia los terrenos social, histórico y antropológico, espacios dominados por el poder y la autoridad de manera más o menos explícita, y cuando se proyecta, se dirige al público de un modo distinto al que emplea la ficción. Las películas de este segundo tipo heredan los modelos narrativos del teatro burgués del siglo diecinueve y de la novela, aunque adaptados a las aspiraciones populistas de la ficción, y apelan a la vida emocional y sentimental de los espectadores, a su subjetividad, incluso cuando tratan de asuntos sociales, históricos o políticos. El documental, en cambio, se dirige al espectador en cuanto ciudadano, en cuanto miembro de un colectivo y elemento constitutivo del espacio público puesto que es un cine íntimamente ligado a la esfera social (Chanan, 2007: 94).

Crow apunta hacia la necesidad de cambiar la visión de la minusvalía que existe en el cine mainstream "por otras basadas en la propia experiencia de la minusvalía, en lugar de con lo que las minusvalías significan para las personas no discapacitadas» (1996: 235). Como nos advierte Esteban, «lo que hay que cambiar son las actitudes, las creencias, los valores, más que el cuerpo en sí» (2004: 33). 
Para un análisis más profundo sobre esta cuestión de la imagen de la discapacidad en el cine debemos destacar las investigaciones realizadas por Margarita Córdoba y Julio Cabero (2009), Cine y diversidad social. Instrumento práctico para la formación en valores; Olga María Alegre de la Rosa, La discapacidad en el cine (2003), y, por su especialización desde una perspectiva de género, el capítulo de Marta Senet Ramos (2015) Woman and disbility in Spanish Cinema (1979-2012), además de la obra fundacional de Martin Norden (1998) que hemos reseñado anteriormente El cine del aislamiento.

\section{METODOLOGÍA}

Siguiendo la definición propuesta por Casetti y Di Chio (1991: 17) podemos entender el análisis como «aquel conjunto de operaciones sobre un objeto determinado y consistente en su descomposición y en su sucesiva recomposición, con el fin de identificar mejor los componentes, la arquitectura, los movimientos, la dinámica, etc.». Nos disponemos en esta investigación a realizar un abordaje interpretativo de los tres filmes documentales mencionados en el objeto de estudio a través de una metodología propia.

Además, se vuelve necesario un análisis que evidencie la aportación subversiva y deconstructiva de estas obras documentales y que muestre que estas obras se contraponen a la mirada clásica, parcial y limitada de la representación tradicional, victimizante, discriminatoria y llena de prejuicios de las personas con discapacidad. Como advierte Colaizzi (1997: 41):

Un texto -cualquier texto- no puede ser simplemente mirado o visto; se tiene que
leer su arquitectura, las fuerzas y los modelos que lo rigen, descifrar los códigos,
que lo constituyen, a los que se sujeta o resiste; quiere decir darse cuenta de que
"veo" no quiere decir "comprendo", que toda representación, todo texto no es
mímesis de la realidad [...] sino escritura, in/scripción cultural, construcción, una
articulación de sentidos hecha a partir de coordenadas histórico/sociales concretas,
siempre ideológicamente orientadas, motivadas y conducidas a intereses concretos.

A partir de estos parámetros, con rigor metodológico, integrando diversas tradiciones disciplinarias en un análisis claramente interdisciplinario, pretendemos adentrarnos en la lectura de estos textos cinematográficos aportando una nueva mirada libre de tabúes y discriminación.

Nos encontramos ante una investigación de las imágenes culturales cinematográficas dominantes creadas dentro de los contextos de la sociedad, a la vez que ponen de relieve los valores sociales imperantes, y este será nuestro análisis; para ello, además de las herramientas metodológicas del análisis visual cinematográfico, utilizaremos como marco teórico y metodológico las teorías fílmicas feministas, los estudios de género y la teoría queer, indagando en la relación cine/género/sociedad y en «la impía alianza del feminismo, la semiótica y el cine» (De Lauretis, 1984: 13).

Realizamos este análisis convencidos, como destacan Zurian y Herrero (2014: 18), de que este tipo de análisis: 
realmente supone una metodología atravesada transversalmente por una gran variedad de campos de investigación intelectual y disciplinas: un sistema de análisis en constante diálogo, pues en cada momento del análisis se introducen variantes epistemológicas que posibilitan o pretenden posibilitar la mejor episteme, la que mejor puede ahondar en el análisis y extraer mejores datos alejados de una doxa personal e individual.

\section{Delimitación Del objeto de estudio}

En la búsqueda en la web de cine online Filmin, bajo el epígrafe Enfermedades y discapacidades podemos encontrar 186 títulos sobre este tema (2/04/20) mientras que, si hacemos una búsqueda cruzada con el tema sexo, podremos encontrar títulos como Hasta la Vista (2012), Vivir y otras ficciones (2017), Dora y la revolución sexual (2015). Nos encontramos, pues, ante un tema que interesa a la sociedad y que está siendo debatido también en las pantallas.

La selección de los documentales objeto de estudio se ha hecho siguiendo dos parámetros, uno por la forma novedosa de mostrar la intersección entre sexo y discapacidad y además hemos querido elegir obras de distintos años y con una separación cronológica importante para también poder realizar un estudio comparativo en el tratamiento del tabú sexual. Las tres obras seleccionadas muestran cada una a su manera el espíritu del momento en que han sido realizadas y, como veremos en nuestro análisis, son cada una la consecuencia de la siguiente y muestran el avance social en nuestro país respecto a la relación entre sexualidad y discapacidad.

AnÁlisis aUdiovisual

Yes we fuck! (2015)

Dirigido por Antonio Centeno y Raúl de la Morena

Nos encontramos ante un documental que, a través de seis historias, en palabras de Teresa de Lauretis, trata de construir «otro horizonte discursivo, otra forma de pensar lo sexual» (1991: 4). Este documental no es novedoso sólo en el fondo, sino también en la forma, y podríamos calificarlo de documental híbrido debido a que ha ido extendiendo un nuevo relato hipertextual, a través de diversos medios y plataformas (web, redes sociales) con participación de distintos usuarios y asociaciones, creando una comunidad donde el nexo es la exploración de la sexualidad en personas con diversidad funcional. Lo que al principio se concibió como un documento audiovisual con una clara intención política, didáctica y visibilizadora ha seguido creciendo y se ha convertido en un movimiento social bajo el que se presentan nuevas obras y se siguen abriendo nuevas vías de visibilización. Kuhn (1991: 87) nos urge de la necesidad de "hacer visible lo invisible» y los autores de este documental han seguido esta máxima feminista a la hora de plantear su trabajo, desmontando tabúes y mostrando y explorando cuerpos no normativos, rom- 
piendo el orden sexogenérico dominante, el régimen heterosexual (Wittig, 2006) e incluso en la difusión de esta obra han sido rompedores y subversivos, pues el 12 de abril de 2018 se comenzó a distribuir gratuitamente el documental con la intención de convertirse en una "herramienta útil en las manos de cualquiera para abrir debates sobre la diversidad y la sexualidad» ${ }^{4}$.

El propio Centeno (O’Hara, 2013) lo explica así:

El documental quiere visualizar, principalmente, el sexo entre personas con diversidad funcional y generar así un nuevo e integrador imaginario colectivo donde tod@s, sin complejos, sin censuras, sin leyes, podamos disfrutar del sexo.

La complejidad de este documental rompedor estriba en cómo muestra el sexo y lo que la diversidad funcional puede aportar a la sexualidad humana. Rompe con la concepción de la sexualidad basada en el coito y plantea otras formas de vivir y sentir la sexualidad, poniendo como ejemplos a los cuerpos diversos, explorando los límites de la sexualidad y del cuerpo. Los protagonistas del documental se muestran orgullosos frente a la cámara y utilizan sus cuerpos diversos como armas empoderantes, abriendo un debate sobre las lógicas de exclusión/inclusión de la mirada y utilizando el cuerpo como una herramienta de liberación.

El sexo se presenta como «juego, diversión, experimentación, política» (min. 9:51) o como «diversidad, imaginación, placer-saber» (min. 10:01). Dando la libertad y la palabra a aquellos a los que se les niega su sexualidad descubrimos que las fronteras y los límites son construcciones sociales, como nos explican en el documental: «Para mí el sexo es un espacio de creación, un espacio en el que me siento libre de poder experimentar [...], aunque tampoco sabría definir dónde empieza y dónde acaba el sexo» (min. 34:54).

Centrándonos en su contenido pornográfico, Gubern (2005: 16) hace hincapié en el carácter didáctico de la pornografía:

Valorada en su calidad de escuela de técnicas eróticas, quebrantadura de inhibiciones sexuales, desmitificadora del dogma monogámico, fuente de gratificación hedonista $\mathrm{y}$, muy especialmente, para los ancianos, enfermos, físicamente desfavorecidos, solitarios o socialmente marginados. El carácter didáctico de la pornografía parece difícilmente cuestionable (y las cortapisas censoras no hacen más que confirmarlo), de modo que no sería aventurado afirmar que la extensión social en las culturas occidentales de técnicas como la felación, el cunnilingus, la sodomía, etc., deba bastante a la didáctica de la escuela pornográfica.

Sin embargo, esta obra rompe con el porno mainstream, muestra lo que otros ocultan o maquillan, mira a la cámara de frente y convierte lo personal en algo político, haciendo de este documental una pieza didáctica de gran interés para romper

${ }^{4}$ Fuente: Facebook, perfil del documental Yes we fuck! Disponible en https://www.facebook.com/yeswfck/. Consultado el 10 de mayo de 2020. 
con los regímenes visuales normativos. Como argumenta Centeno (O'Hara, 2013): «Si queremos cambiar el imaginario colectivo, nada mejor que imágenes contundentes contextualizadas por la idea política que sustenta el proyecto YWF».

Además, debemos hacer hincapié en cuándo se presenta este documental: en el ańo 2015 la sexualidad de las personas con discapacidad seguía siendo un gran tabú y apenas había sido representada. En el documental podemos reseñar Almas con sexo (TVE, 2003) y en la ficción en el año 2012 se había presentado el filme Las sesiones de Ben Lewin, un retrato amable de la pérdida de virginidad del periodista y poeta tetrapléjico y con un pulmón de acero, Mark O’Brien; sin embargo, aunque este filme tuvo una gran repercusión al mostrar escenas de desnudos frontales e incluso penetraciones en la pantalla de cine, se trata de una visión edulcorada y donde, además, aparece la figura del cura, una representación institucional, de las que huye YWF. Al presentar en el documental a los personajes relacionándose fuera de espacios institucionales o medicalizados y plantear de una forma política las reivindicaciones del colectivo, politizando la sexualidad y la figura de el/la asistente sexual y creando alianzas con los feminismos y activismos LGTBI y queer, YWF realiza una mirada subversiva que inicia un camino que más adelante será tomado por otras producciones.

\section{Jo també vull sexe! (2016)}

\section{Dirigido por Montse Armengou y Ricard Belis}

«Tú pagas al médico para que te arregle la muela. Yo tengo que pagar para que toquen mi cuerpo. Yo estaba muy triste, muy deprimida. Y desde que hago esto, me siento muy bien, es como una terapia» (min. 19:56). Existen muchas maneras de explicar un concepto, pero la máxima «una imagen vale más que mil palabras» sigue muy vigente. Palacio (2011: 8-9), afirma que «los medios audiovisuales se han convertido en actores centrales de la sociedad y de la cultura contemporánea; a su vez, por su capacidad de llegar a un público muy vasto son capaces de transformar valores, hábitos y formas de interrelación en nuestras sociedades».

En el año 2016 la sociedad española comenzó a preguntarse sobre la figura $\mathrm{de} \mathrm{el/la} \mathrm{asistente} \mathrm{sexual,} \mathrm{un} \mathrm{debate} \mathrm{que} \mathrm{sigue} \mathrm{abierto,} \mathrm{pero} \mathrm{que} \mathrm{en} \mathrm{ese} \mathrm{momento,} \mathrm{con}$ los cambios legislativos en Europa, era una cuestión candente. Ya existían algunas obras audiovisuales donde aparecía esta figura como, por ejemplo, el documental One Life: For One Night Only (BBC, 2007) (que más tarde se convertiría en la road movie Hasta la vista (Geoffrey Enthoven, 2011), Scarlet Road (Catherine Scott, 2011) o la antes mencionada Las sesiones (Ben Lewin, 2012). Sin embargo, el impacto de YWF había sido tan profundo que terminó convirtiéndose en una referente, como podemos comprobar en el hecho de que aparece una de sus proyecciones en este documental.

«Ha habido madres que han masturbado a los hijos antes de buscarles una asistenta sexual. Yo lo respeto, pero para mí es anormal» (min. 6:50). La dificultad a la hora de abordar el espinoso tema de la asistencia sexual con tantas implicaciones morales y éticas toma una nueva y necesaria visión en este documental, que da la voz a sus protagonistas y ahonda en sus necesidades sexuales y de afecto. 
Como dice Sánchez Noriega, «los medios tienen mucha importancia en la socialización de normas, valores y expectativas de conducta» (1997: 149). Los medios, y especialmente el medio televisivo, están asumiendo un papel creciente como instrumentos socializadores en detrimento de los que comúnmente se denominan agentes tradicionales, como lo son la familia, la escuela y la Iglesia. "Los medios de masas audiovisuales e informáticos han sustituido a las instituciones que tradicionalmente habían llevado el peso del proceso socializador, instaurando nuevas formas de comunicación y de interpretación de la realidad» (Ferrés 2000: 40).

Este documental se presenta dentro del espacio Sense ficció (Sin ficción), un título que deja clara la intención del programa de mostrar la realidad y tomar el pulso a la sociedad con documentales de producción propia para la cadena TV-3.

A «Sense ficció», entenem el documental com una eina per ajudar a progressar la nostra societat. El periodisme que practiquem busca donar veu a les persones que normalment no en tenen i treure a la llum els conflictes, les polèmiques i les històries que se'ns han volgut ocultar ${ }^{5}$.

De esta manera subraya el equipo del programa la idea principal de «hacer visible lo invisible» a través del documental, lo que relaciona esta obra, además de por su temática, con YWF. Asimismo, al incluir el tema de la sexualidad y la discapacidad en este programa podemos ver hasta qué punto YWF había logrado calar en la sociedad y abrir el debate de la asistencia sexual. De nuevo observamos cómo las imágenes de cuerpos desnudos no normativos son utilizadas como armas empoderantes desde la pantalla; como afirma Sutton (2007), la resistencia y la protesta políticas van siempre acompañadas de un intenso compromiso corporal: hay que "poner el cuerpo" y JTVS apuesta por una reivindicación empoderante desde la corporalidad.

Las diferentes audiencias de YWF y JTVS hacen que el tratamiento del sexo sea muy diferente y muestran una evolución hacia una normatividad heterosexual que es comprensible por el medio donde se emite el documental; sin embargo, creemos que al existir una directora, la perspectiva de género se ha impuesto y resulta un documental muy igualitario y empoderante. Si bien es cierto que YWF da la voz a los colectivos sexuales más marginales, JTVS muestra a hombres y mujeres con discapacidad con iguales necesidades sexuales, lo que es un hecho importante para una televisión generalista.

5 Web Sense Ficció. Disponible online en https://www.ccma.cat/tv3/sense-ficcio/programa/ Consultado el 11 de mayo de 2020. «En "Sin ficción”, entendemos el documental como una herramienta para ayudar a progresar nuestra sociedad. El periodismo que practicamos busca dar voz a las personas que normalmente no tienen y sacar a la luz los conflictos, las polémicas y las historias que se nos han querido ocultar» (traducción de los autores). 


\section{Crip Camp: A Disabled Revolution (2020)}

Dirigido por James Lebrecht y Nicole Newnham

Comenzaremos este análisis llamando la atención sobre la traducción del título con el que se conoce este documental en España: Campamento maravilloso.

Una de las principales premisas del movimiento queer es rechazar las definiciones: «Nombrar es matar», defiende Marla Morris (Talburt y Steinberg, 2005: 48). La importancia de la semántica y la función del lenguaje es una de las aportaciones más importantes queer. Butler (2004), en Lenguaje, poder e identidad, se pregunta si hablar es actuar, ¿qué consecuencias se derivan de ello? y se plantea la función del lenguaje en la constitución de la subjetividad y su articulación con el poder. Es por eso por lo que no podemos dejar pasar como algo anecdótico, burdo o simplemente absurdo cómo se renombra (porque no es una traducción) este documental en Espańa.

La traducción sería Campamento lisiado: Una revolución de discapacidad. El nombre original del campamento es Campamento Jenet, así que debemos asumir que los productores del filme decidieron nombrar el documental en una clara alusión a la teoría queer y específicamente a la teoría crip. Al tomar el término crip (lisiado/tullido) como un emblema y autorreferenciarse, se disloca el lugar de poder desde el cual parte cuando se hace como insulto y así podemos observar cómo se desnaturaliza ese insulto y se utiliza el término como forma de rebelarse contra el poder; además, en el título original se utiliza la palabra revolución, con la importante carga semántica que supone de cambio, lucha y superación.

Sin embargo, en España también pensamos que de una manera consciente, el campamento de los lisiados o tullidos (entendido desde lo queer) se ha convertido en un campamento maravilla, una palabra que es descendiente por vía semiculta del latín mirabilia, plural neutro del adjetivo mirabilis «digno de admiración», convirtiendo una acción de protesta y subversión en un acto de que debe ser aprobado por los otros/as. Esta palabra nos remite a los términos con los que los adultos se comunican con los nińos/as para de forma condescendiente alabar sus logros, infantiliza los logros de esta comunidad y sensacionaliza el activismo realizado por estas personas.

En Screendaily ${ }^{6}$, Fionnuala Halligan aporta un dato importante sobre la obra, lo inesperado de sus consecuencias: «Una mirada reveladora e inspiradora al movimiento por los derechos de los discapacitados de los años 70 [...]. Su estructura es clásica, pero lo que presenta es inesperado».

El llamado «efecto mariposa» parece la premisa de este documental, porque la elección del campamento y la posibilidad de asistir cambia no sólo las vidas de sus campistas, sino de toda la sociedad americana. La premisa de cambio, de giro copernicano, estaba en la base de la reunión, como explica Larry Allison (EFE, 26 de marzo de 2020), director de aquel campamento.

${ }^{6}$ https://www.screendaily.com/reviews/crip-camp-sundance-review/5146381.article. 
Intentamos promover ahí un ambiente en el que los adolescentes pudieran ser adolescentes sin todas las etiquetas y estereotipos, lo cual fue un producto de esa era gracias a la experimentación social. Nos dimos cuenta de que el problema no venía de las personas con discapacidades sino de quienes no tenían discapacidad. Era nuestro problema así que nosotros debíamos cambiar.

Uno de los puntos de mayor interés del documental es el material grabado en el campamento por el colectivo People's Video Theater. Mostrar la América de 1971, dos ańos después de Woodstock, tiene algo de entrańable y sentimental, pero también de político, porque, con los años el movimiento hippie ha sido tildado por sectores conservadores como irresponsable o vago; sin embargo, las imágenes nos muestran cómo los responsables del campamento, «melenudos» hippies, tratan de manera innovadora y trabajan con jóvenes con parálisis cerebral o afectados por la polio, juegan al béisbol o les ayudan con sus dudas sexuales, propias de la adolescencia, siempre con eficacia y profesionalidad.

Hay que destacar que el campamento aparece como una isla de integración $\mathrm{y}$ respeto en una sociedad que trataba a las personas con discapacidad casi como a ciudadanos de segunda clase, y es aquí donde comienza lo inesperado, los campistas no quieren que al salir se acabe su sueño y deciden seguir su lucha.

Dentro de nuestro análisis hemos elegido este filme por la manera en que se trata la sexualidad. Tras YWF y JTVS, CC incide en la sexualidad como uno más de los temas que trata, la naturalidad con la que ya no es tabú referirse a la masturbación o al coito viene a romper con los discursos anteriores de una forma radical. Sin mostrar escenas sexuales o pornográficas, las declaraciones de los entrevistados, las imágenes de archivo y las actuales transmiten una sensación de superación que contribuyen decididamente a una visión más amplia de la sexualidad humana y a un nuevo paradigma a la hora de enfrentar la sexualidad en la discapacidad. Es muy llamativo cómo se utilizan las imágenes de archivo para, por ejemplo, mostrar cómo una pareja que se formó en el campamento entre dos personas con discapacidad intelectual sigue siendo pareja 49 años después, marcando un nuevo hito, el unir sexualidad con amor y compromiso. Si bien el sexo no es el elemento principal empoderante en este documental, podemos ver, sin embargo, un hecho muy importante por su invisibilidad en la sociedad y en el audiovisual, la supervivencia y la lucha. Al mostrar dos momentos separados temporalmente, CC presenta una imagen activa, positiva y empoderante de la diversidad funcional, mostrando a sus protagonistas como activistas comprometidos que logran convertir sus ideales en leyes, cambiando la sociedad, un hecho que en el audiovisual estaba siempre reservado a aquellas personas que no presentaban una discapacidad.

\section{RESULTADOS/CONCLUSIONES}

Somos seres sexuados desde el mismo momento que nacemos; sin embargo, durante demasiado tiempo a las personas con discapacidad se les ha negado su sexualidad, además de infantilizarlos. Esto, sumado al tabú inherente a la socie- 
dad hacia el sexo, ha articulado mitos y creencias que han victimizado y discriminado a las personas con discapacidad, negándoles el acceso a su derecho a una sexualidad plena.

El cine, como espejo de la sociedad, ha contribuido de manera fehaciente a esta discriminación elaborando estereotipos negativos respecto a la discapacidad y negando la sexualidad de este colectivo, ofreciendo imágenes distorsionadas o directamente discriminatorias durante un primer periodo para más tarde pasar a un discurso moralizante, de superación personal o infantilizante. Ha sido un largo proceso hasta que las personas con discapacidad han podido ponerse tras la cámara y contar su realidad o frente a ella en documentales que han mostrado que no sólo son personas sexuadas, sino que su manera de entender el sexo, no centrada en el coito, puede suponer la respuesta para los nuevos discursos sobre sexualidades diversas.

Durante este trabajo se ha detectado la carencia de una investigación comprehensiva sobre la sexualidad y la discapacidad y acerca de los factores culturales que influencian las actitudes de la sociedad hacia la sexualidad de las personas con diversidad funcional.

Recientemente en España se ha producido una mayor atención social, cobertura mediática, académica y política hacia este tema donde la figura de el/la asistente sexual ha sido clave. Creemos fundamental la presencia de la discapacidad en el cine, para concienciar, y también para inculcar valores como la integración y no discriminación; además, mostrar la sexualidad de las personas con discapacidad ayuda a romper con regímenes de imágenes normativos, respecto al cuerpo o la sexualidad, y esto ayuda a otras minorías a empoderarse y mostrarse en la pantalla.

Podemos asegurar que el camino emprendido por YWF ha llevado hacia un cambio de paradigma en la representación de la sexualidad de las personas con discapacidad en el cine, rompiendo el tabú de la representación de los cuerpos no normativos y abriendo las puertas para nuevas discusiones como el erotismo, las relaciones de pareja o el amor romántico, que estaban igualmente vetadas a las personas con discapacidad.

La visión subversiva y política de estas obras y sus fuertes reivindicaciones las convierten en herramientas didácticas muy útiles para el empoderamiento de las personas con discapacidad y suponen un cambio fundamental a la hora de mostrar el sexo en la pantalla, abriendo, además, el camino a cambios legislativos y políticos que incluyan la adopción de medidas de acción positiva orientadas a evitar o compensar las desventajas de una persona con discapacidad para participar plenamente en la vida política, económica, cultural y social y lograr una mayor igualdad de oportunidades y acabar con la discriminación a causa de su discapacidad, además de dotarlos de la ayudas necesarias para tener una sexualidad totalmente plena. 


\section{REFERENCIAS BIBLIOGRÁFICAS}

Alegre de la Rosa, O.M. (2003). La discapacidad en el cine. Barcelona: Octaedro.

Alonso, M. ${ }^{a}$ L. y Pereira, M. ${ }^{a}$ C. (2000). «El cine como medio-recurso para la educación en valores. Un enfoque teórico y tecnológico». Pedagogía social: Revista Interuniversitaria, (5): 127-148.

Anderson, P. y Kitchin, R. (2000). «Disability, space and sexuality: access to family planning services». Social science \& medicine, 51(8): 1163-1173.

Arnau Ripollés, M.S. (2005). «Otras voces de mujer: el feminismo de la diversidad funcional/ Other Women's Voices: The Feminism of Functional Diversity». Asparkia. Investigació feminista, (16): 15-26.

Arnau Ripollés, M.S. (2003). «Una Construcción Social de la Discapacidad: el Movimiento de Vida Independiente», en VIII Jornadas de Fomento de la Investigación de la Facultad de Ciencias Humanas y Sociales. Fórum de Recerca.

Asís, R. de (2017). «¿Es la asistencia sexual un derecho?». Revista Española de Discapacidad, 5(2): 7-18.

Benjamin, W. (2003). La obra de arte en la época de su reproductibilidad técnica. México: Itaca.

Bernert, D.J. (2011). «Sexuality and disability in the lives of women with intellectual disabilities». Sexuality and Disability, 29(2): 129-141.

BLock, P. (2002). «Sexuality, parenthood, and cognitive disability in Brazil». Sexuality and Disability, 20(1): 7-28.

Block, P. (2000). «Sexuality, fertility, and danger: Twentieth-century images of women with cognitive disabilities». Sexuality and Disability, 18(4): 239-254.

Block, P. et al. (2012). "Disability, Sexuality and Intimacy», en Pollard, N. and Sakellariou, D., Politics of occupation-Centred practice: Reflections on occupational engagement across cultures. New Jersey: John Wiley \& Sons. 162-179.

Bourdieu, P. (1999). Meditaciones pascalianas. Barcelona: Anagrama.

Bourdieu, P. (1977). «Remarques provisoires sur la perception sociale du corps». Actes de la Recherche en Sciences Sociales, 14: 51-54.

Breschand, J. (2004). El documental. La otra cara del cine. Barcelona: Paidós.

Brodwin, M.G. y Frederick, P.C. (2010). «Sexuality and societal beliefs regarding persons living with disabilities». Journal of Rehabilitation, 76(4), 37.

Carter Overstreet, L. (2008). «Splitting Sexuality and Disability: A Content Analysis and Case Study of Internet Pornography featuring a Female Wheelchair User». Thesis, Georgia State University.

Centeno, A. (2004). «Simbolismos y alianzas para una revuelta de los cuerpos». Educació Social. Revista de d'Intervenció Socioeducativo. (58): 101-118.

Chanan, M. (2007). «El documental y el espacio público». Archivos de la Filmoteca, 57-58(1): 68-99.

Cole, T.M. y Cole, S. (1993). «Sexuality, disability, and reproductive issues through the lifespan». Sexuality and Disability, 11(3): 189-205.

Cordoba Pérez, M. y Cabero Almenara, J. (2009). Cine y diversidad social. Instrumento práctico para la formación en valores. Sevilla: Editorial Mad.

Crow, L. (1996). «Nuestra vida en su totalidad: renovación del modelo social de Discapacidad», en Morris, J., Encuentros con desconocidas. Feminismo y discapacidad. Madrid: Narcea. 229-250 
De Lauretis, T. (1991). «Queertheory: lesbian and gay sexualities. An introduction». Differences. A Journal of Feminist Cultural Studies, 3(2): 3-17.

Douglas, M. (1988). Simbolos naturales: exploraciones en cosmología. Madrid: Alianza.

Drummond, J.D. y Brotman, S. (2014). «Intersecting and embodied identities: A queer woman's experience of disability and sexuality». Sexuality and Disability, 32(4): 533-549.

Dukes, E. y McGuire, B.E. (2009). «Enhancing capacity to make sexuality-related decisions in people with an intellectual disability». Journal of Intellectual Disability Research, 53(8): 727-734.

EFE (26/3/2020). “"Crip Camp”: el Woodstock de la discapacidad revisado por los Obama». La voz de Asturias, recuperado de https://www.lavozdeasturias.es/noticia/cultura/2020/03/26/ crip-camp-obama-discapacidad/0003_202003G26P479919.htm. Última consulta: $01 / 7 / 2020$.

Esteban, M. ${ }^{2}$ L. (2004). Antropología del cuerpo. Género, itinerarios corporales, identidad y cambio. Barcelona: Bellaterra.

Eтhis, E. (2009). Sociologie du cinéma et de ses publics. París: Édition Armand Colin.

Ferrés, J. (1996). Televisión subliminal. Socialización mediante comunicaciones inadvertidas. Barcelona: Paidós.

Fiduccia, B.W. (2000). "Current issues in sexuality and the disability movement». Sexuality and disability, 18(3): 167-174.

Foucault, M. (1992). Vigilar y castigar: nacimiento de la prisión. Madrid: Siglo XXI.

Franco, D.G., Cardoso, J. y Neto, I. (2012). «Attitudes towards affectivity and sexuality of people with intellectual disability». Sexuality and Disability, 30(3): 261-287.

García-SAntesmases, A. (2015). «El cuerpo en disputa: cuestionamientos a la identidad de género desde la diversidad funcional». Intersticios. Revista sociológica de pensamiento crítico, 9(1): 41-62.

García-Santesmases, A. y Branco de Castro, C. (2016). «Fantasmas y fantasías: controversias sobre la asistencia sexual para personas con diversidad funcional». Pedagogia $i$ Treball Social, 5(1): 3-33.

Gilmore, L. y Chambers, B. (2010). «Intellectual disability and sexuality: Attitudes of disability support staff and leisure industry employees». Journal of Intellectual and Developmental Disability, 35(1): 22-28.

Goldman, A. (1976). «Quelques problèmes de sociologie du cinéma». Sociologie et société, 8(1), abril. 71-80.

Greydanus, D.E., Rimsza, M.E. y Newhouse, P.A. (2002). «Adolescent sexuality and disability». Adolescent Medicine Clinics, 13(2): 223.

Gubern, R. (2005). La imagen pornográfica y otras perversiones ópticas. Madrid: Cátedra.

Guldin, A. (2000). Self-claiming sexuality: Mobility impaired people and American culture. Sexuality and Disability, 18(4), 233-238.

Healy, E. et al. (2009). «Sexuality and personal relationships for people with an intellectual disability. Part I: service-user perspectives». Journal of Intellectual Disability Research, 53(11): 905-912.

Iañez Domínguez, A. (2010). Prisioneros del cuerpo: la construcción social de la diversidad funcional. Madrid: Diversitas.

IsLER, A. et al. (2009). «A study on sexuality with the parents of adolescents with intellectual disability». Sexuality and Disability, 27(4): 229. 
Kazukauskas, K.A. y Lam, Ch.S. (2010). «Disability and sexuality: Knowledge, attitudes, and level of comfort among certified rehabilitation counselors». Rehabilitation Counseling Bulletin, 54(1): 15-25.

KEDDE, H. et al. (2012). «Sexual health problems and associated help-seeking behavior of people with physical disabilities and chronic diseases». Journal of sex \& marital therapy, 38(1): 63-78.

KIJAK, R. (2013). «The sexuality of adults with intellectual disability in Poland. Sexuality and disability", 31(2): 109-123.

KIJAK, R. (2011). «A desire for love: considerations on sexuality and sexual education of people with intellectual disability in Poland». Sexuality and disability, 29(1): 65-74.

KIм, E. (2011). «Asexuality in disability narratives». Sexualities, 14(4): 479-493.

Koller, R. (2000). «Sexuality and adolescents with autism». Sexuality and Disability, 18(2): 125-135.

Kunn, A. (1991). Cine de mujeres. Feminismo y cine. Madrid: Cátedra.

Le Breton, D. (2002). Antropología del cuerpo y modernidad. Buenos Aires: Nueva Visión.

Ledesma, J.A. (2009). La imagen social de las personas con discapacidad. Madrid: Ediciones Cinca.

LÖFgren-MÅtenson, L. (2004). «May I? About sexuality and love in the new generation with intellectual disabilities». Sexuality and Disability, 22(3): 197-207.

Majiet, S. (1996). «Sexuality and disability». Agenda, 12(28): 77-80.

MaLL, S. y Swartz, L. (2012). «Sexuality, disability and human rights: strengthening healthcare for disabled people». SAMJ: South African Medical Journal, 102(10): 792-793.

Mauss, M. (1968). «Les techniques du corps», en Mauss, M., Sociologie et anthropologie. París: PUF. 363-386.

Mauss, M. (2003). "As good as it goes. Queer Theory and Critical Disability». GLQ: A Journal of Lesbian and Gay Studies, 9(1-2): 79-105.

McCaвe, M. (1999). «Sexual knowledge, experience and feelings among people with disability». Sexuality and Disability, 17(2): 157-170.

McCabe, M., Cummins, R.A. y Deens, A. (2000). «Sexuality and quality of life among people with physical disability». Sexuality and Disability, 18(2): 115-123.

McRuer, R. (2006). Crip Theory: Cultural signs of Queerness and Disability. New York: New York University Press.

Meinerz, N.E. (2010). "Corpo e outras (de) limitaçóes sexuais: uma análise antropológica da revista Sexuality and Disability entre os anos de 1996 e 2006». Revista Brasileira de Ciências Sociais, 25(72): 117-178.

Mitry, J. (1989). Estética y psicología del cine. Madrid: Siglo XXI.

Monga, T. (1996). «Physical medicine and rehabilitation state of the arts review: Sexuality and disability». Journal of Sex Research, 33: 267-270.

Nichols, B. (2007). «Cuestiones de ética y cine documental». Archivos de la Filmoteca. 57-58(1): 29-45.

Norden, M.F. (1998). El cine del aislamiento. El discapacitado en la historia del cine. Madrid: Escuela Libre Editorial.

Nosek, M.A. et al. (2001). «Vulnerabilities for abuse among women with disabilities». Sexuality and Disability, 19(3): 177-189. 
Parchomiuk, M. (2012). «Specialists and sexuality of individuals with disability». Sexuality and Disability, 30(4), 407-419.

Platero M.R. y Rosón Villena, M. (2012). «De la 'parada de los monstruos' a los monstruos de lo cotidiano: la diversidad funcional y la sexualidad no normative». Feminismo/s, 19 (jun. 2012): $127-142$.

Rabiger, M. (2004). Directing the documentary. USA: Focal Press.

Rembis, M.A. (2010). «Beyond the binary: rethinking the social model of disabled sexuality». Sexuality and Disability, 28(1): 51-60.

Robinault, I.P. (1978). Sex, society, and the disabled. New York: Harper \& Row.

Sánchez Noriega, J.L. (1997). Crítica de la seducción mediática. Madrid: Tecnos.

Sakellariou, D. (2006). «If not the disability, then what? Barriers to reclaiming sexuality following spinal cord injury». Sexuality and disability, 24(2): 101-111.

Sakellariou, D. y Simó, S. (2006). «Sexuality and disability: A case of occupational injustice». British Journal of Occupational Therapy, 69(2): 69-76.

Samuels, E. (2003). «My body, my closet. Invisible Disability and the Limits of Coming-Out Discourse». GLQ: A Journal of Lesbian and Gay Studies, 9(1-2): 233-255.

SAndahl, C. (2003). «Queering the Crip or Cripping the Queer? Intersections of Queer and Crip Indentities in Solo Autobiographical Performance». GLQ: A Journal of Lesbian and Gay Studies, 9(1-2): 25-56.

SAnders, T. (2007). «The politics of sexual citizenship: commercial sex and disability». Disability \& Society, 22(5): 439-455.

Shakespeare, T. (2000). (1998). «Poder y prejuicio: los temas de género, sexualidad y discapacidad», en L. Barton (comp.) Discapacidady Sociedad. Madrid: Moratta, 205-299.

Shakespeare, T. (2000). «Disabled sexuality: Toward rights and recognition». Sexuality and disability, 18(3): 159-166.

Shakespeare, T. (1999). "The sexual politics of disabled masculinity». Sexuality and disability, 17(1): 53-64.

SHILDRICK, M. (2007). «Contested pleasures: The sociopolitical economy of disability and sexuality». Sexuality Research \& Social Policy, 4(1): 51-75.

SHindel, W. et al. (2010). «Medical student sexuality: How sexual experience and sexuality training impact US and Canadian medical student's comfort in dealing with patient's sexuality in clinical practice». Academic Medicine, 85(8): 1321-1330.

Senet Ramos, M. (2015). "Woman and disbility in Spanish Cinema (1979-2012)», en Cascajosa Virino, C. (ed.), A new gaze: Women creators of film and televisión in democratic Spain, Cambridge: Cambridge Scholar publising. 137-147.

Sorlin, P. (1977). Sociología del cine. La apertura para la historia de mañana. París: Aubier- Montaigne.

Sutton, B. (2007). «Poner el Cuerpo: Women's Embodiment and Political Resistance in Argentina». Latin American Politics and Society, 49(3): 129-162.

Talburt, S. y Steinberg, S.R. (eds.) (2005). Pensando queer. Sexualidad, cultura y educación. Barcelona: Graó.

Taleporos, G. y McCabe, M.P. (2001). «Physical disability and sexual esteem. Sexuality and Disability", 19(2): 131-148. 
Taleporos, G. y McCabe, M. (2002). «The Impact of Sexual Esteem, Body Esteem, and Sexual Satisfaction on Psychological Well-Being in People with Physical». Disability. Sexuality \& Disability, 20(3): 177-183.

Tepper, M.S. (2000). «Sexuality and disability: The missing discourse of Pleasure». Sexuality and disability, 18(4): 283-290.

Tepper, M.S. (1999). «Letting go of restrictive notions of manhood: Male sexuality, disability and chronic illness». Sexuality and Disability, 17(1): 37-52.

TAYLOR, M. (2012). «The $S$ words: Sexuality, sensuality, sexual expression and people with intellectual disability». Sexuality and Disability, 30(2): 237-245.

Valvano, A.K. et al. (2014). «Health professions students' perceptions of sexuality in patients with physical disability». Sexuality and Disability, 32(3): 413-427.

Williams, D. (1994). Somebody Somewhere: Breaking Free from the World of Autism. New York: Three Rivers Press.

Winges-Yanez, N. (2014). "Why all the talk about sex? An authoethnography identifying the troubling discourse of sexuality and intellectual disability». Sexuality and Disability, 32(1): 107-116.

Wittig, M. (2006). El pensamiento heterosexual y otros ensayos. Barcelona: Editorial Egales.

Yoshida, K., Li, A. y Odette, F. (1999). "Cross-cultural views of disability and sexuality: Experiences of a group of ethno-racial women with physical disabilities». Sexuality and Disability, 17(4): 321-337.

Zurian, F. y Herrero, B. (2014). «Los estudios de género y la teoría fílmica feminista como marco teórico y metodológico para la investigación en cultura audiovisual». Área Abierta, vol. 14(3): 6-21. 